\title{
BMJ Open Occupational challenges of healthcare workers during the COVID-19 pandemic: a qualitative study
}

\author{
Maren Jeleff (D) ," Marianna Traugott (D) , ${ }^{2}$ Elena Jirovsky-Platter (D) , \\ Galateja Jordakieva (1) , ${ }^{3}$ Ruth Kutalek (D) ${ }^{1}$
}

To cite: Jeleff M, Traugott M, Jirovsky-Platter $\mathrm{E}$, et al. Occupational challenges of healthcare workers during the COVID-19 pandemic: a qualitative study. BMJ Open 2022;12:e054516. doi:10.1136/ bmjopen-2021-054516

- Prepublication history and additional supplemental material for this paper are available online. To view these files, please visit the journal online (http://dx.doi.org/10.1136/ bmjopen-2021-054516).

Received 16 June 2021 Accepted 08 February 2022

A) Check for updates

(C) Author(s) (or their employer(s)) 2022. Re-use permitted under CC BY-NC. No commercial re-use. See rights and permissions. Published by BMJ.

${ }^{1}$ Unit Medical Anthropology and Global Health, Department of Social and Preventive Medicine, Centre for Public Health, Medical University of Vienna, Wien, Austria

${ }^{2}$ Department of Internal Medicine IV with Infectious Diseases and Tropical Medicine, Clinic Favoriten, Vienna, Austria ${ }^{3}$ Department of Physical Medicine, Rehabilitation and Occupational Medicine, Medical University of Vienna, Wien, Austria

Correspondence to Ms Maren Jeleff; maren.jeleff-entscheff@ meduniwien.ac.at

\section{ABSTRACT}

Objectives To address structural determinants and healthcare workers' (HCWs) physical, mental, emotional and professional challenges of working during the COVID-19 pandemic.

Design Exploratory qualitative study with semistructured interviews. Collected data were analysed using thematic analysis.

Setting This qualitative study was undertaken with HCWs who mainly worked in intensive care units in six non-profit hospitals in Vienna, Austria. Data were collected from June 2020 to January 2021.

Participants A total of $30 \mathrm{HCWs}$ (13 medical doctors, 11 qualified nursing staff, 2 nurse assistants, 2 physiotherapists and 2 technical/cleaning staff) who were in direct and indirect contact with patients with COVID-19 were included.

Results Three overall themes resulted as relevant: challenges due to lack of preparedness, structural conditions, and physical and mental health of HCWs. Lack of preparedness included delayed infection prevention and control (IPC) guidelines, shortages of personal protective equipment combined with staff shortages (especially of nursing staff) and overworked personnel. Physical and mental strains resulted from HCWs being overworked and working permanently on alert to face medical uncertainties and the critical conditions of patients. HCWs lacked recognition on multiple levels and dealt with stigma and avoidance behaviour of colleagues.

Conclusion To mitigate HCWs' occupational health risks and staff turnover, we propose context-specific recommendations. The number of available essential workers in care of patients with COVID-19, especially nursing staff, should be carefully planned and increased to avert chronic work overload. Timely training and education in IPC for all HCWs is important. Providing supportive supervision is as essential as appropriate recognition by higher level management and the public.

\section{INTRODUCTION}

Since early 2020, the COVID-19 pandemic has been challenging healthcare systems worldwide. Multiple factors such as rapid spread, limited treatment options for a formerly unknown disease, high quantity of contagious patients and prolonged duration of the pandemic pose a burden on healthcare
Strengths and limitations of this study

- We outline context-specific challenges faced by healthcare workers (HCWs) of different work groups by using an exploratory qualitative approach.

- The research considers changes over time by collecting data over a 6-month period; therefore, the data include topics relevant to both the beginning of the pandemic and as the pandemic unfolded.

- Female interview participants predominated the participant group (21 women vs 9 men). This was due to there being a higher number of female staff in the healthcare field in general, particularly in nursing.

- Some interviews may have been shorter than usual or may not have yielded in-depth information because interviews took place under rushed conditions and with tired HCWs.

- We were unable to consider any additional differences in experiences between professions and different occupational groups.

systems. Particularly in the beginning of the pandemic, healthcare workers (HCWs) were considered a vulnerable group, mainly because they were continuously exposed while caring for patients and often lacked appropriate personal protective equipment (PPE). ${ }^{1}$

In many countries the public applauded and heroised HCWs. However, most HCWs do not identify themselves as heroes. Still, they are overworked and bear the physical and mental burden of their commitment. ${ }^{2}$ Initially driven by enthusiasm and optimism, most HCWs feel exhausted due to the continuation of the pandemic. ${ }^{3}$ Dealing with the physical and mental burden of working extensively in a highly demanding situation, they are struck by fear of both infecting family members and dealing with social stigmas. ${ }^{45}$ Additionally, a recently published meta-analysis found that female HCWs are especially affected by anxiety and depression, and a higher prevalence of these disorders is seen in nurses than in doctors. ${ }^{6}$ 
Due to the enormous pressure globally, many nurses are resigning their jobs. ${ }^{7}$ The situation is exacerbated by structural shortages of qualified nurses, a problem that pre-existed the pandemic with a bottleneck of 6 million nurses worldwide. ${ }^{8}$

Austria is an illustrative example of how COVID-19 is posing hardship to a relatively advanced and wellequipped healthcare system. Austria uses the Bismarck model, with health expenditures mainly being paid from taxes and mandatory social security contributions. A fundamental feature of this system is its comprehensive health insurance coverage (99.9\%) and thus accessibility to good quality care. ${ }^{9-11}$ In 2017 , Austria was among the countries with the highest number of hospital beds (7.4 beds per 1000 people), which is an indicator for available resources regarding inpatient services. ${ }^{10}$

Nevertheless, COVID-19 overwhelmed Austria's healthcare system and to date the capacity of intensive care unit (ICU) beds is reaching its limits. ${ }^{12}$ Furthermore, Austrian hospitals were ill-prepared for the pandemic; the most prominent example of this is the temporary shortages of PPE. $^{1314}$

HCWs' health, well-being and safety are paramount for a well-functioning healthcare system and for ensuring patient safety. ${ }^{4}$ Consequently, mitigating risks on multiple levels-especially regarding staff turnover and mental health-is necessary. ${ }^{6}{ }^{15}$

In this study, we therefore aim to address the structural determinants as well as the physical, mental, emotional and professional challenges that affect HCWs when working during the COVID-19 pandemic. Based on our results, we propose context-specific recommendations.

\section{METHODS}

We conducted an exploratory qualitative study with semistructured interviews to gain insights into HCWs' challenges of working with patients with COVID-19 in six Viennese non-profit hospitals.

MJ, EJ-P and RK are medical anthropologists and qualitative researchers who conducted the interviews. The data collection took place between June 2020 and January 2021. We interviewed HCWs who were either in direct contact with COVID-19-infected patients or in indirect contact through handling contaminated material (work units are detailed in table 1). In the beginning of the pandemic, only a few of the 21 non-profit hospitals in Vienna were designated to admit patients with COVID-19; therefore, we recruited interview participants from these hospitals. In one hospital, we had a key informant who arranged contacts from hospital staff, aiming for maximum variation in participants (qualified nurses, nurse assistants, cleaning staff, physiotherapists and medical doctors). Later, as additional hospitals were designated to care for patients with COVID-19, we broadened our sample and included interview partners through snowball sampling.

Participants were interviewed via telephone, online call (Webex) or in person in a private room at the hospital

\begin{tabular}{|c|c|c|}
\hline Variables & Description & $\begin{array}{l}\text { No of } \\
\text { participants }\end{array}$ \\
\hline \multirow[t]{2}{*}{ Gender } & Male & 9 \\
\hline & Female & 21 \\
\hline \multirow[t]{9}{*}{ Profession } & Qualified nurse & 11 \\
\hline & Nurse assistant & 2 \\
\hline & Physiotherapist & 2 \\
\hline & Cleaning/technical staff & 2 \\
\hline & Medical doctors: & \\
\hline & Infectious disease expert & 3 \\
\hline & Anaesthesiologist & 2 \\
\hline & Neurologist & 2 \\
\hline & Other (eg, surgeon) & 6 \\
\hline \multirow[t]{5}{*}{ Work units* } & COVID-19 intensive care & 13 \\
\hline & COVID-19 non-intensive care & 5 \\
\hline & $\begin{array}{l}\text { COVID-19 intensive care and } \\
\text { non-intensive care }\end{array}$ & 2 \\
\hline & COVID-19 othert & 4 \\
\hline & Other & 6 \\
\hline \multirow[t]{4}{*}{ Age (years) } & $21-30$ & 7 \\
\hline & $31-40$ & 10 \\
\hline & $41-50$ & 8 \\
\hline & $51-60$ & 5 \\
\hline
\end{tabular}

${ }^{*}$ Refers to the units that HCWs were assigned to.

†Includes 'pop-up' COVID-19 units and intermediate care units. $\ddagger$ Non-COVID-19 units with direct or indirect contact with patients with COVID-19.

HCWs, healthcare workers.

where they worked (carried out under precautionary measures). Interviews were scheduled during working hours and at times convenient to the participants. Those who agreed to take part in the study signed the participant consent form. All interviews were audio-recorded, except for one with a participant who felt more comfortable not being recorded. In this case, we took written notes and sent them to the participant for validation and further clarification after the interview. Interviews lasted between 30 and $60 \mathrm{~min}$ and were led by a topic guide (see online supplemental material). However, questions were adapted to the flow of the conversation and the importance the interviewees gave to a specific topic. We conducted the interviews until saturation of data was reached, meaning that no new themes emerged or no new information was discovered, so further data collection would have been redundant.

Upon the conclusion of the interview process, we outsourced the transcriptions of the interviews. The transcription service provider signed a non-disclosure agreement stating that interviews and transcripts are kept confidential. All transcripts were anonymised and 
labelled using numerical code names, and personal identifiers were removed.

We imported transcripts into ATLAS.ti (V.8.4.4) and analysed them with thematic analysis using inductive and deductive coding. We used thematic analysis to recognise, analyse and interpret patterns of meaning. The first author (MJ) performed the analysis of the interview transcripts. There was a continuous dialogue between MJ and RK throughout the analysis process. We informed the deductive codes by the topic guide questions; all other codes we derived inductively through repeated examination of the data. Codes were united to overall themes that included lack of preparedness, overworked personnel, staff shortage and redeployment, stigma, avoidance behaviour and lack of recognition. The research considers changes over time; for example, PPE shortages were more influential in the beginning of the pandemic, while overworked personnel was more influential in the later phase of the pandemic.

\section{Patient and public involvement}

No patient involved.

\section{RESULTS}

\section{Description of participants}

We collected data from 30 participants in direct and indirect contact with patients infected with COVID-19. A total of 13 medical doctors, 11 qualified nurses (mainly working in ICUs) and 6 other professions were included (table 1). Female participants predominated overall (21 women vs 9 men).

\section{Lack of preparedness}

While confronted with a hitherto unknown pandemic, HCWs were troubled by delayed or unavailable infection prevention and control (IPC) guidelines that were adapted to a major infectious disease outbreak. This included guidelines for proper donning and doffing of PPE, guidelines for medical procedures producing aerosols and IPC strategies for patient transfers. Consequently, HCWs faced many uncertainties, and those units in charge of treating patients with COVID-19 often had to make autonomous decisions:

The department of hygiene gave instructions only after we became a COVID-19 ward, on the same day or maybe two days before, whilst we were already wondering about it for weeks. Examples include which respirator tools to use or the need of different filters, those which would last longer, as we don't want to disconnect the ventilators daily [...] Those points were addressed super delayed by the department of hygiene. (Qualified Nurse 4)

Most participants specified that their team and immediate superiors dealt with the situation excellently. However, some complained about chaos that arose on higher levels of the hospital hierarchy; participants wished for better guidance from leadership and management:

It is something you expect to be handled by management and not from the personnel on the ward [...] You expect the hospital pays attention that the work procedures are properly adjusted-not that the employees take care of them. (Medical Doctor 1)

Relatedly, one cleaning person stated that her colleagues did not know much about the virus and consulted her with questions. She wished for simple COVID-19-specific training for her and her colleagues. Further, cleaning staff often perceived that they were extremely feared, mainly because of a lack of understanding about transmission pathways.

Another demanding factor was lack of coordination between hospitals. Especially in the first phase of the pandemic (early 2020), there was a lack of clarity on ICU bed capacities. Medical Doctor 18 considered the second phase a missed chance to better prepare for the predicted peak phase in autumn and felt that other hospitals in Vienna were unprepared to take on patients with COVID-19:

It was really badly organized. For example, when our intensive care unit was full for the first time, everyone was taken by surprise. Oh, there are no more intensive care beds, where should they be transferred to now? And then the hospital $[\mathrm{XY}]$ took them [the patients] and they were completely unprepared. And one would think, folks, you had all summer to worry about this and prepare for it. And now, in autumn, the beds are occupied again and now-once againwe need more wards. (Medical Doctor 18)

One medical doctor concluded, 'Well, you do wonder how slow the mills in Austria are grinding and how little foresight one can have' (Medical Doctor 5).

\section{Physical and mental protection}

During the first phase of the pandemic, there was a shortage of face masks and the fear of insufficient face masks. One medical doctor reflected on how to define shortage of face masks in Austria: 'Once you start using masks that had expired 14 years ago, which we did, I would say we ran out of masks' (Medical Doctor 5). Others mentioned having to use face masks of insufficient quality, wear masks that did not properly fit or reuse disposable masks. FFP3 masks were especially rare and often only available for rooms with patients on non-invasive ventilators where circulation of aerosols was highest:

When we ran out of FFP3 masks we received products of minor quality. We had incidents where a colleague was in the room and the elastic cord of the mask broke. Or the filter of the mask fell out-that happened to me-and thank God it happened before I was in the patient room. But these are all things that shouldn't happen. And then another problem was 
that these masks didn't fit everyone either [...] I had a colleague who did not want to enter the patient room because the mask didn't fit properly. (Qualified Nurse 10)

Fear of mask shortages led employees to stockpile masks and management to restrict their distribution. In one hospital, cleaning personnel or other medical support personnel were often denied adequate face masks.

However, these were concerns in the early stages of the pandemic. When asked directly whether they felt safe at their workplace, most HCWs stated they felt sufficiently protected. Those working at ICUs especially felt better protected than those working in wards 'outside' because they knew the infectious status of their patients and worked while wearing protective gear.

In addition to increased availability of physical protection, participants requested supervision, which employers rarely offered. Though not everyone mentioned needing supportive supervision, most considered its provision important:

Of course, there are some things I miss from our employing institution as it is its responsibility to protect us. Not only to provide the protective gear but also mental protection. [...] It has the responsibility to ensure we do not get harmed mentally and physically. (Qualified Nurse 23)

\section{Overworked personnel, staff shortage and redeployment of staff}

Especially in November 2020, HCWs were working over the limit of their capacities. Many reported being mentally and physically exhausted and needing longer regeneration times than usual:

I often thought I got infected with COVID-19 because I am so exhausted. But no, it is this working with the mask and planning all your actions precisely for the moment. You have to think about so many things, what are the next steps. It is really also a mental burden. In cycling they refer to the term 'the red zone' and I would say that we are often in the red zone, but we do not recognize it anymore $[\ldots]$ because you get used to it. You have to get used to it because otherwise you have to resign. Or you will break. So either you are strong and you stick it out or you have to leave.

(Qualified Nurse 17)

HCWs not only worked extra hours or worked without having proper breaks, but also functioned in a permanent state of alarm. In addition to dealing with challenges related to infection risk and altered working procedures, HCWs faced medical uncertainties and emotional challenges due to the critical condition of patients. The difference from pre-COVID-19 was in the quantity of dying patients, as highlighted by the metaphorical phrase, 'Patients are dying like flies' (Qualified Nurse 17). Another mental burden was seeing young people and people without underlying medical conditions die or having to witness how patients slowly died in full consciousness and isolation. Additionally, most HCWs were not trained in palliative care, and dealing with the unpredictability of the disease added to being mentally overburdened.

HCWs also spoke about a missing work-life balance and the consequences of being overworked. Some thought being overworked made them more vulnerable to getting infected with COVID-19, and others mentioned the physical pain of chronic overload:

We are now faced with some sick leaves. It is the high adrenalin and cortisone levels of this crisis, the ongoing emergency mode that is exhausting at some point. Basically, our bodies are giving up. [...] There are people that would like to, but they are just sick now. They do not have COVID-19, but they are sick. They have digestive issues; one has had ongoing diarrhea for threeweeks and he looks pale as a linen sheet. (Medical Doctor 27)

Participants further mentioned that being overworked combined with a shortage or unavailability of staff, especially when personnel got sick, was a primary problem. Many often needed to make multiple requests to the administration to procure more staff:

Contrary to what we were promised at the beginning, 'no matter what, you get what you need,' we didn't get any additional staff and we had to do it with the core team. We all work way over our regular working hours and that is very intense. Somehow it has worked out for the last half year, I mean, especially this department, they are all incredibly motivated and passionate. They are infectiologists with their heart and soul, and they love their work, but now you realize slowly, now it's going to the core, it's slowly not working any longer. (Medical Doctor 24)

To remedy staff shortages in one ward, qualified nurses were often recruited from other wards. Those who had free choice and switched on a voluntary basis with the option to switch back viewed this more positively. However, many suddenly had to work with patients with COVID-19 without having a professional background in infectious diseases and thus lacked technical knowledge in this regard. Often, qualified nurses found themselves in a new team with little time for proper training, which produced extra stress:

The psychological challenge is [...] I actually have nothing to do with infections. [...] Of course I believe that I am very good at what I do and that I am able to adjust, but I just don't have this background, this technical knowledge regarding infections. (Qualified Nurse 23)

We got people (qualified nurses) [...] who used to work in an acute geriatric ward with old people who are in rehab, and then they came here [...] They 
didn't want that, they didn't want to work here, they were afraid. They were used to different work in terms of speed and skills. (Qualified Nurse 17)

Though medical doctors from other units (eg, rheumatologists) were also redeployed to COVID-19 units, their situation was perceived as more stable because they could stay as a team at their unit. However, these professions experienced the same sudden shift to providing care regardless of their professional background.

\section{Stigma and avoidance}

HCWs experienced stigma in their private lives and observed avoidance behaviour in some colleagues. Especially in the beginning of the pandemic, some physicians neglected to attend to patients due to fear of becoming infected:

We had a patient who was a cardiology patient suffering a heart attack and the cardiologists did not want to attend to the patient because they were too scared of COVID-19. You end up thinking, this is your patient who happens to have COVID-19 but it is simply not adequate patient care. Because you are scared of this stupid virus. And I keep on going in everyday. (Medical Doctor 18)

One qualified nurse did not see the nursing officer during the first months of COVID-19 and thought her ward was being avoided. Other challenges participants mentioned were getting appointments for CT, having X-rays done on patients with COVID-19 and getting blood examined at the laboratory. The situation improved over time, mainly because of constant communication with the concerned colleagues.

HCWs were often perceived as high-risk contacts and faced stigma in their social surroundings. Stigmatisation also extended to family members. Labels such as 'Coronalady' or 'Corona children' give an impression of how HCWs and family members were sometimes perceived by their social environment. Others reported that their children were not invited to their friends' homes, and their personal appointments at a doctor's office were rudely cancelled:

We know, for example, that a medical doctor faced tremendous hostility. That's not that easy to handle. And of course, we are being avoided. I am no longer invited anywhere because I am working in a COVID-19 ward. (Qualified Nurse 17)

The predominant fear of HCWs was that they might infect family members. This fear sometimes led to selfstigmatisation or avoidance behaviour such as sleeping in separate bedrooms or not kissing their partner. One HCW recounted that she considered herself a role model. This had to do with the perception that as an HCW she should know about infection pathways and because she saw the worst consequences of a COVID-19 infection. Thus, she thought that HCWs had to be especially cautious about their behaviour.

\section{Lack of recognition}

Gratitude and appreciation were important topics for most HCWs. They positively mentioned support from direct supervisors and between team members was encouraging. However, many participants missed receiving recognition by higher management levels or securing financial rewards as promised by politicians:

You just don't feel valued [...] It does not have to be a monetary reward, though that would be something, because it was much more exhausting, but frankly a 'thank you' for showing up or saying, 'I know it is exhausting.' That is something that would qualify a leader. (Qualified Nurse 10)

Qualified nurses especially perceived that their work was not recognised and feared their services (for the public) will fall into oblivion once the crisis is over:

These are just my fantasies [to receive a recognition or award]. It would just be nice to acknowledge all the work we have done, but I am afraid that is utopian. The pandemic will pass, and no one will give a hoot about it. That's the reality. (Qualified Nurse 17)

Further, most HCWs largely missed receiving appreciation from the public. Many participants thought 'clapping at 18:00' or being identified as a hero did not show sincere gratitude and considered personalised appreciation as genuine support (eg, a banner in front of the hospital from an Austrian football club).

\section{DISCUSSION}

This study focuses on occupational challenges faced by HCWs working in six Viennese hospitals during the COVID-19 pandemic. Our paper is one of only few qualitative studies addressing this topic in the European Union. ${ }^{16}{ }^{17}$ By using a qualitative exploratory approach, we outlined context-specific challenges experienced by HCWs of different work groups. The research considered changes over time by collecting data over a period of 6 months, and therefore includes topics relevant to both the beginning of the crisis and as the pandemic unfolded.

Findings indicate that stress factors result from poor structural conditions, a lack of pandemic planning at governmental and institutional levels, and clinical challenges resulting from physical, mental, and emotional implications. Lacking recognition from upper-level management and facing social stigmas from the public add to these stressors. Our findings largely correspond with results from other international studies on related topics, demonstrating how most experiences are shared on a global level. ${ }^{16-30}$

In the early stages of the pandemic, lack of preparedness played a major role, mainly in terms of PPE shortages and delayed IPC guidelines. PPE shortage was a global 
phenomenon, and the usage of inadequate PPE was also addressed in other research. ${ }^{18-21}$ According to a study on HCWs' motivation for delivering care during COVID-19, not feeling protected by the government or hospital was related to lower hesitation to work. The authors conclude that more efforts should be made on governmental and hospital levels to protect HCWs, especially when it comes to preventing infections in HCWs. ${ }^{22}$ Another study cites low confidence in knowledge of IPC as the main barrier to willingness to work during infectious disease outbreaks. ${ }^{23}$ Consequently, providing proper IPC training and adequate PPE to all HCWs is not only indispensable for providing a safe workplace but also influential to workforce availability in the long run.

In our research, staff shortage and overworked staff became routine factors that affected working conditions as the pandemic unfolded. Other studies report similar findings. ${ }^{24-26}$ In the long run, depletion of staff affects the mental and physical health of HCWs and carries with it negative implications on workplace safety. Further, overworked personnel inversely affects quality of care. This increases the need for more hospital personnel and readjustments of staff schedules to shorter shifts to ensure a safe work place. ${ }^{20}{ }^{21}$ We also found that some qualified nurses without professional infectious disease background or training were recruited from other wards to remedy staff shortages. Redeployment of staff without specific training may lead to absenteeism, especially once the crisis is over. ${ }^{31}$ Therefore, it is even more important that redeployment is based on voluntary decision. ${ }^{32}$ To tackle the problem of nurses not having diverse backgrounds, experiences and skills, one Chinese hospital implemented standardised nursing procedures for work routines and content. Other hospitals provided clearly defined responsibilities of staff and training programmes for protective measures and handling equipment. ${ }^{20} 33$

Stigmatisation and self-stigmatisation mainly occurred outside the hospital but added to the mentioned stressors. COVID-19-related stigmatisation of HCWs is a global social consequence of this pandemic. In many countries, HCWs were avoided or insulted and experienced violence or harassment. ${ }^{27-29}$ This is especially worrisome since HCWs respond to health crises to save lives while exposing themselves to the risk of infection. ${ }^{30}$ Stigma and self-stigmatisation may be exacerbated by questions of guilt (eg, who is responsible for another person's infection or death), which seems to be a characteristic of this pandemic. However, the governmental measures of social distancing, necessary for diminishing infection rates, make the boundaries between social distance and social stigma less tangible.

Another sensitive topic was avoidance of colleagues who treat patients with COVID-19, which was most relevant at the beginning of the pandemic. To our knowledge, this finding has not yet been addressed by other authors. This avoidance may stem from the anxiety of possibly infecting oneself or family members, respect of this then unknown threat and limited scientific knowledge that was available at the time. It may also be the result of not feeling properly prepared to work in an infectious disease context. While some HCWs are more resilient to working in this exceptional situation, others found it more difficult and burdensome. Avoidance behaviour of colleagues needs to be addressed because it leads to conflict, additional workloads, and undertreatment and delayed care of vulnerable patients.

In our study's context, HCWs felt a lack of recognition, acknowledgement and appreciation. This includes not only financial compensation but also immaterial rewards such as gratitude from higher management levels and personalised appreciation by politicians and the public. Labelling HCWs as heroes is a well-intended gesture that can backfire once the expectations of perfection cannot be fulfilled. The concept of heroism conceals the fact that most HCWs do not have a choice other than to do their jobs (eg, due to professional work ethics or economic reasons). It leaves other aspects, such as HCWs' working conditions or systemic failures, unaddressed. Showing genuine appreciation and solidarity by complying with COVID-19 mitigation measures (eg, reducing personal contact, social distancing, wearing face masks, getting vaccinated) should come into better focus. In addition, showing gratitude to HCWs by acknowledging their working conditions is a key element of protecting the mental health of HCWs; this is known as fostering resilience. ${ }^{345}$

All mentioned stressors influence HCWs' physical and mental health and may affect HCWs' willingness to continue their work. In the USA, 18\% of HCWs have resigned their jobs since the pandemic began. ${ }^{36}$ A recent survey in Austria found that $44 \%$ of nurses think monthly or more frequently about quitting their jobs. ${ }^{37}$ Protecting HCWs directly and indirectly should be a priority during and after this pandemic.

In terms of 'mental protection', one study concludes that the mental health of HCWs should be addressed with a holistic approach and a socio-ecological understanding of well-being. ${ }^{25}$ Such an approach considers multiple aspects that affect the well-being of HCWs besides clinical challenges (eg, staff shortages, taking enough rest, access to PPE and external factors such as public support). ${ }^{25} 2632$ Further, providing contextualised psychological services that are adjusted to HCWs' specific needs (eg, uninterrupted resting) is important. ${ }^{38}$ Psychological interventions should also be adapted to sociodemographic disparities and differences among work groups. ${ }^{23}$ Other studies found that HCWs experience moral injury as a consequence of their commitment. ${ }^{16}{ }^{39}$ Insufficient protection and other factors that violate one's ethical principles (eg, not being able to provide good quality care due to being overworked) lead to negative self-perception and distrust in the system. ${ }^{39}$ Once the crisis is over, a major task should therefore be aftercare of HCWs to address moral injury and rebuild trust in the system. ${ }^{1634}$

\section{Limitations}

For this study, we focused on the core topics but are aware that stressors of HCWs are more complex. Doing research during a pandemic posed several challenges, including interviews took place under rushed conditions, after 
clinical work, and with overworked or tired HCWs. Consequently, some interviews may have been shorter than usual or may not have yielded in-depth considerations. Further, there are likely more differences in experiences between professions and different occupational groups that we were unable to consider.

\section{Conclusions and recommendations}

Despite the medical difficulties and unpredictable aspects of preparing for a pandemic, preparation (eg, with guidelines and standard operating procedures) is necessary to ensure a structural framework that enables HCWs to feel prepared, protected and cared for. This framework is also needed to ensure optimised psychosociological working conditions for HCWs and support them during these challenging times.

In our context, mainly organizational-level recommendations are necessary to prepare for later phases of the pandemic or new emerging threats. Managing the shortages on multiple levels will be paramount. Four thematic actions emerge as important. First is tackling the shortages of PPE to ensure physical protection. Second is mitigating the shortages of human workforce to avert chronic occupational overload. For this, adequate provision of medical personnel, especially nursing staff, is essential. Voluntarism also plays a key role in terms of redeployment of staff; HCWs should be given the option of switching back or at least have their personal preferences considered. Third is timely provision of necessary IPC guidelines and training in palliative care. Service staff should receive tailored IPC training to both cope with fears and remain safe. In general, professionally handling and addressing fear is necessary for overcoming avoidance behaviour. Simulation exercises for both doctors and qualified nurses, along with professional debriefing, could better prepare HCWs for stressful situations. Finally, caring for the mental health of HCWs is vital, especially by offering supportive supervision that is convenient to HCWs' work schedules. Gratitude from superiors, politicians and the public is indispensable for showing support and fostering resilience.

Acknowledgements We thank all healthcare workers who took time to participate in our study. We also thank The Vienna Science and Technology Fund for funding this research and scribbr.com for proofreading the article.

Contributors RK conceptualised the research. MJ, RK and EJ-P conducted the interviews. MJ analysed and interpreted the data, MJ wrote the manuscript. MT, GJ, EJ-P and RK reviewed and edited the manuscript. RK accepts full responsibility for the finished work and/or the conduct of the study as guarantor, had access to the data, and controlled the decision to publish. All authors read and approved the final manuscript.

Funding This article has received funding from the Vienna Science and Technology Fund (WWTF) (COVID-19 Rapid Response 2020/EI-COV20-026).

Disclaimer The funders did not play a role in the decision to publish the article.

Competing interests None declared.

Patient consent for publication Not required.

Ethics approval This study involves human participants and was approved by the Ethics Committee of the Medical University of Vienna (1409/2020) and the Ethics Committee of the Town of Vienna (EK20-093-VK). Participants gave informed consent to participate in the study before taking part.
Provenance and peer review Not commissioned; externally peer reviewed.

Data availability statement Data are available upon reasonable request. The data that support the findings of this study are available from the corresponding author, upon reasonable request.

Supplemental material This content has been supplied by the author(s). It has not been vetted by BMJ Publishing Group Limited (BMJ) and may not have been peer-reviewed. Any opinions or recommendations discussed are solely those of the author(s) and are not endorsed by BMJ. BMJ disclaims all liability and responsibility arising from any reliance placed on the content. Where the content includes any translated material, BMJ does not warrant the accuracy and reliability of the translations (including but not limited to local regulations, clinical guidelines, terminology, drug names and drug dosages), and is not responsible for any error and/or omissions arising from translation and adaptation or otherwise.

Open access This is an open access article distributed in accordance with the Creative Commons Attribution Non Commercial (CC BY-NC 4.0) license, which permits others to distribute, remix, adapt, build upon this work non-commercially, and license their derivative works on different terms, provided the original work is properly cited, appropriate credit is given, any changes made indicated, and the use is non-commercial. See: http://creativecommons.org/licenses/by-nc/4.0/.

\section{ORCID iDs}

Maren Jeleff http://orcid.org/0000-0002-6789-9167

Marianna Traugott http://orcid.org/0000-0003-0534-1966

Elena Jirovsky-Platter http://orcid.org/0000-0002-8304-2518

Galateja Jordakieva http://orcid.org/0000-0001-5884-8256

Ruth Kutalek http://orcid.org/0000-0002-3325-3173

\section{REFERENCES}

1 Smith C. The structural vulnerability of healthcare workers during COVID-19: observations on the social context of risk and the equitable distribution of resources. Soc Sci Med 2020;258:113119.

2 Jacobs A. They died saving others from Covid. will anyone count them? The New York Times, 2021.

3 Bennett P, Noble S, Johnston S, et al. COVID-19 confessions: a qualitative exploration of healthcare workers experiences of working with COVID-19. BMJ Open 2020;10:e043949.

4 WHO. Keep health workers safe to keep patients safe. Geneva, 2020

5 Adams JG, Walls RM. Supporting the health care workforce during the COVID-19 global epidemic. JAMA 2020;323:1439.

6 Pappa S, Ntella V, Giannakas T, et al. Prevalence of depression, anxiety, and insomnia among healthcare workers during the COVID-19 pandemic: a systematic review and meta-analysis. Brain Behav Immun 2020;88:901-7.

7 Viele Pflegekräfte wollen wegen zu viel stress aufgeben. Available: https://www.derstandard.at/story/2000124953415/vielepflegekraefte-wollen-wegen-stress-aufgeben [Accessed 22 Mar 2021].

8 COVID-19 pandemic one year on: ICN warns of exodus of experienced nurses compounding current shortages. Available: https://www.icn.ch/news/covid-19-pandemic-one-year-icn-warnsexodus-experienced-nurses-compounding-current-shortages [Accessed 23 Mar 2021].

9 Bundesministerium für Soziales, Gesundheit, Pflege, Konsumentenschutz. Das Gesundheitswesen im Überblick, 2021. Available: https://www.gesundheit.gv.at/gesundheitsleistungen/ gesundheitswesen/gesundheitssystem [Accessed 19 Apr 2021].

10 OECD. Health at a glance 2019: OECD indicators. Paris: OECD Publishing, 2019.

11 Mayer S. Austrian health care system [unpublished lecture notes] (notes provided at lecture 15 March 2019). Medical University of Vienna, Center for Public Health.

12 AGES. AGES Dashboard COVID19, 2021. Available: https://covid19dashboard.ages.at/dashboard_Hosp.html [Accessed 19 Apr 2021].

13 Redl B. Nur AKH-Bedienstete MIT Patientenkontakt bekommen Schutzmasken. Available: https://www.derstandard.at/story/ 2000116662263/nur-akh-bedienstete-mit-patientenkontaktbekommen-schutzmasken [Accessed 23 Mar 2021].

14 Spitäler haben zu wenig Schutzausrüstung. Available: https://wien. orf.at/stories/3039633/ [Accessed 23 Mar 2021].

15 The Gobal nursing shortage and nurse retention. Int Council Nurs 2021.

16 Kreh A, Brancaleoni R, Magalini SC, et al. Ethical and psychosocial considerations for hospital personnel in the Covid-19 crisis: moral injury and resilience. PLoS One 2021;16:e0249609. 
17 Fernández-Castillo R-J, González-Caro M-D, Fernández-García $\mathrm{E}$, et al. Intensive care nurses' experiences during the COVID-19 pandemic: a qualitative study. Nurs Crit Care 2021;26:397-406.

18 Hoernke K, Djellouli N, Andrews L, et al. Frontline healthcare workers' experiences with personal protective equipment during the COVID-19 pandemic in the UK: a rapid qualitative appraisal. BMJ Open 2021;11:e046199.

19 Ahmed J, Malik F, Bin Arif T, et al. Availability of personal protective equipment (PPE) among US and Pakistani doctors in COVID-19 pandemic. Cureus 2020;12:e8550.

20 Stennett J, Hou R, Traverson L, et al. Lessons learned from the resilience of Chinese hospitals to the COVID-19 pandemic: a scoping review. (Preprint). JMIRx Med 2021

21 Tabah A, Ramanan M, Laupland KB, et al. Personal protective equipment and intensive care unit healthcare worker safety in the COVID-19 era (PPE-SAFE): an international survey. J Crit Care 2020;59:70-5.

22 Malesza M. Factors informing healthcare workers' willingness to work during the COVID-19 pandemic. medRxiv 2021.

23 Que J, Shi L, Deng J, et al. Psychological impact of the COVID-19 pandemic on healthcare workers: a cross-sectional study in China. General Psychiatry 2020;33:e100259.

24 Liu Q, Luo D, Haase JE, et al. The experiences of health-care providers during the COVID-19 crisis in China: a qualitative study. Lancet Glob Health 2020;8:e790-8.

25 Vera San Juan N, Aceituno D, Djellouli N, et al. Mental health and well-being of healthcare workers during the COVID-19 pandemic in the UK: contrasting guidelines with experiences in practice. BJPsych Open 2021;7:e15.

26 Vindrola-Padros C, Andrews L, Dowrick A, et al. Perceptions and experiences of healthcare workers during the COVID-19 pandemic in the UK. BMJ Open 2020;10:e040503.

27 Bagcchi S. Stigma during the COVID-19 pandemic. Lancet 2020.

28 Singh R, Subedi M. COVID-19 and stigma: social discrimination towards frontline healthcare providers and COVID-19 recovered patients in Nepal. Asian J Psychiatr 2020;53:102222.
29 Taylor S, Landry CA, Rachor GS, et al. Fear and avoidance of healthcare workers: an important, under-recognized form of stigmatization during the COVID-19 pandemic. J Anxiety Disord 2020;75:102289.

30 McKay D, Heisler M, Mishori R, et al. Attacks against health-care personnel must stop, especially as the world fights COVID-19. Lancet 2020;395:1743-5.

31 Tujjar O, Simonelli M. Absenteeism of frontline healthcare workers during Covid-19: the need for a framework of support. SN Compr Clin Med 2020;2:2715-7.

32 Kisely S, Warren N, McMahon L, et al. Occurrence, prevention, and management of the psychological effects of emerging virus outbreaks on healthcare workers: rapid review and meta-analysis. BMJ 2020;369:m1642.

33 Feng $M$, Wang $Q$, Su J. Nursing management in isolation wards for coronaviurs disease 2019 in a general hospital under a joint rescue model. Chinese J Nurs 2020;55:817-21.

34 Greenberg N. Mental health of health-care workers in the COVID-19 era. Nat Rev Nephrol 2020;16:425-6.

35 McCanlies EC, Gu JK, Andrew ME, et al. The effect of social support, gratitude, resilience and satisfaction with life on depressive symptoms among police officers following Hurricane Katrina. Int J Soc Psychiatry 2018;64:63-72.

36 Galvin G. Nearly 1 in 5 health care workers have quit their jobs during the pandemic, 2021. Available: https://morningconsult.com/2021/10/ 04/health-care-workers-series-part-2-workforce/ [Accessed 22 Dec 2021].

37 Schalek K. Online-Umfrage Der offensive Gesundheit ICH glaub ICH Krieg die Krise 2021.

38 Chen Q, Liang M, Li Y, et al. Mental health care for medical staff in China during the COVID-19 outbreak. Lancet Psychiatry 2020;7:e15-16.

39 Greenberg N, Docherty M, Gnanapragasam S, et al. Managing mental health challenges faced by healthcare workers during covid-19 pandemic. BMJ 2020;368:m1211 